\title{
Endoscopic submucosal dissection for papillary adenocarcinoma of the stomach: is it really safe?
}

\author{
Hyun Jung Lee ${ }^{1}$ Gwang Ha Kim ${ }^{1}$ Do Youn Park ${ }^{2}$ Y Young Keum Kim² • \\ Hye Kyung Jeon ${ }^{1} \cdot$ Bong Eun Lee ${ }^{1} \cdot$ Geun Am Song ${ }^{1}$
}

Received: 8 December 2016/Accepted: 26 February 2017/Published online: 7 March 2017

(c) The International Gastric Cancer Association and The Japanese Gastric Cancer Association 2017

\begin{abstract}
Background Papillary adenocarcinoma of the stomach has been treated according to the same endoscopic submucosal dissection (ESD) indication criteria as other differentiatedtype adenocarcinomas. We aimed to compare lymph node metastasis (LNM) in patients with early gastric cancer (EGC) with papillary adenocarcinoma (EGC-P) with that in patients with EGC with nonpapillary adenocarcinoma (EGC-NP) and to consider the potential limitation of current ESD indication criteria in the treatment of EGC-P. Methods In total, 1583 patients who underwent gastrectomy for EGC from 2005 to 2014 were included. Clinicopathologic characteristics of 56 patients with EGC-P were compared with those of 1527 patients with EGC-NP. The safety of ESD was evaluated, by application of current ESD indication criteria to EGC-P.

Results The frequency of submucosal invasion was significantly higher in EGC-P than in both EGC-NP with differentiated-type histologic appearance and EGC-NP with undifferentiated-type histologic appearance ( $71.4 \%$ vs $50.8 \%$ and $37.6 \%$, respectively). In addition, the frequency
\end{abstract}

Electronic supplementary material The online version of this article (doi:10.1007/s10120-017-0709-6) contains supplementary material, which is available to authorized users.

Gwang Ha Kim

doc0224@pusan.ac.kr

1 Department of Internal Medicine, Pusan National University School of Medicine, and Biomedical Research Institute, Pusan National University Hospital, 179, Gudeok-ro, Seo-Gu, Busan 49241, South Korea

2 Department of Pathology, Pusan National University School of Medicine, and Biomedical Research Institute, Pusan National University Hospital, 179, Gudeok-ro, Seo-Gu, Busan 49241, South Korea of LNM in EGC-P was $17.9 \%$, higher than that in both EGC-NP with differentiated-type histologic appearance and EGC-NP with undifferentiated-type histologic appearance $(9.7 \%$ and $11.1 \%$, respectively). When the current ESD indication criteria were applied to the 56 patients with EGC-P, 17 patients met the current indications. Of these patients, two (11.8\%) had LNM and three (17.6\%) had lymphovascular invasion (LVI). When LNM and LVI were combined, one of seven patients (16.7\%) meeting the absolute ESD indications and three of ten patients $(30.0 \%)$ meeting the expanded ESD indications would not be cured after ESD.

Conclusions The use of ESD should be more carefully applied in patients with EGC-P meeting the ESD indication criteria, especially the expanded indication criteria, after pretreatment workup compared with other differentiatedtype adenocarcinomas, owing to the higher frequencies of submucosal invasion, LNM, and LVI in EGC-P.

Keywords Early gastric cancer · Papillary adenocarcinoma $\cdot$ Endoscopic submucosal dissection . Lymph node $\cdot$ Metastasis

\section{Introduction}

Eastern countries, including Korea and Japan, have a high incidence of gastric cancer; additionally, the detection rate of early gastric cancers (EGCs) via national gastric cancer screening programs for secondary prevention has been increasing [1]. Since the first decade of this century, the indications for endoscopic resection, especially endoscopic submucosal dissection (ESD), for EGCs have expanded because of additional developments in endoscopic treatment techniques and the 
accumulation of data concerning the risk of lymph node metastasis (LNM) [2]. Currently, tumors resected endoscopically or surgically are assessed histopathologically according to the Japanese classification of gastric cancer, the World Health Organization classification, and the Lauren classification [3-6]. Many studies have reported the benefits and short-term and long-term outcomes of ESD, and ESD is considered a safe treatment modality for differentiated-type EGCs [4, 5, 7-9].

Traditionally, tubular adenocarcinoma and papillary adenocarcinoma are classified as having differentiatedtype histologic appearance; poorly differentiated adenocarcinoma, signet ring cell carcinoma, and mucinous adenocarcinoma are classified as having undifferentiatedtype histologic appearance $[10,11]$. Papillary adenocarcinoma, in particular, is classified as differentiated type in the Japanese classification and intestinal type in the Lauren classification, suggesting ESD to be a safe treatment modality for EGC with papillary adenocarcinoma (EGC-P) [10, 11]. However, there have been several reports that patients with papillary adenocarcinoma have poorer prognosis compared with those with other differentiated types; patients with papillary adenocarcinoma showed more LNM and liver metastasis and lower overall 5-year survival rate than those with nonpapillary adenocarcinoma [12-16]. Because of the rarity of papillary adenocarcinoma, the clinical importance of EGC-P has not been emphasized. Considering that papillary adenocarcinoma has a more aggressive nature than other gastric adenocarcinomas, whether it is safe to treat EGC-P according to the same ESD indication criteria used for EGC with other differentiated types, such as tubular adenocarcinoma, is an important question. Therefore, we aimed to compare the clinicopathologic characteristics of patients with EGC-P with those of patients with EGC with other histologic types, and to investigate the safety of ESD for EGC-P according to current ESD indication criteria.

\section{Patients and methods}

\section{Study population}

From January 2005 to February 2014, 1644 patients with EGC underwent gastrectomy at Pusan National University Hospital (Busan, Korea). Of these, 31 patients with multiple synchronous EGCs, 4 patients with EGC in the remnant stomach, and 28 patients with diagnosis of a different cancer in other organs were excluded. In total, 1583 patients with EGC were ultimately included in the study. These patients were classified into two groups: EGC-P and EGC with nonpapillary adenocarcinoma (EGC-NP)
1644 patients underwent surgery for EGCs

between January 2005 and February 2014

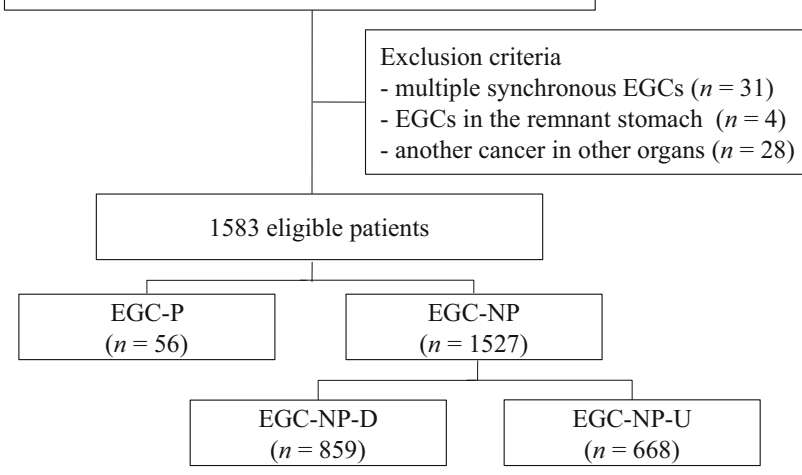

Fig. 1 Flowchart showing patients enrolled in this study. EGCs early gastric cancers, $E G C-N P$ early gastric cancer with nonpapillary adenocarcinoma, $E G C-N P-D$ early gastric cancer with nonpapillary adenocarcinoma with differentiated-type histologic appearance, $E G C$ $N P-U$ early gastric cancer with nonpapillary adenocarcinoma with undifferentiated-type histologic appearance, $E G C-P$ early gastric cancer with papillary adenocarcinoma

(Fig. 1). The EGC-NP group was further subdivided into differentiated-type histologic appearance (EGC-NP-D) and undifferentiated-type histologic appearance (EGC-NP-U). The study protocol was reviewed and approved by the Institutional Review Board of Pusan National University Hospital.

\section{Surgical procedures}

Laparoscopy-assisted or open gastrectomy was performed with lymphadenectomy, resection, and reconstruction, as previously reported [17]. In laparoscopy-assisted gastrectomy, a laparoscope and trocars were inserted through small incisions in the abdominal wall with the patient under general anesthesia. The decision concerning the extent of the surgical operation was based on the degree of cancer progression, histopathologic diagnosis of the biopsy specimen, tumor location, and risk of LNM, morbidity, and death. In cases with proximal tumor location, near-total or total gastrectomy was performed with Billroth I, Billroth II, or Roux-en-Y reconstruction. Subtotal gastrectomy with Billroth I or Billroth II reconstruction was performed for tumors located in the middle third or lower third of the stomach. D1 or D2 lymphadenectomy were performed on a case-by-case basis.

\section{Macroscopic and histopathologic evaluation}

The macroscopic shapes of lesions were categorized as either protruding (I), nonprotruding and nonexcavated (II), or excavated (III). Type II lesions were subclassified as slightly elevated (IIa), flat (IIb), or slightly depressed 
(IIc). Lesions were classified into three groups on the basis of macroscopic evaluation: elevated (I, IIa), flat (IIb), and depressed (IIc, III) types. Resected specimens were fixed in a $10 \%$ formalin solution and serially sectioned at 5-mm intervals to assess tumor involvement at the lateral and vertical margins. Tumor size, depth of invasion, presence of ulceration, lymphovascular invasion (LVI), and LNM were evaluated microscopically.

The tumors were classified histopathologically according to the Japanese classification of gastric carcinoma [10]. Tubular adenocarcinoma (well-differentiated and moderately differentiated adenocarcinoma) and papillary adenocarcinoma were classified as differentiated type, and poorly differentiated adenocarcinoma, signet ring cell carcinoma, and mucinous adenocarcinoma were classified as undifferentiated type. Papillary adenocarcinoma was defined as a tumor in which more than $50 \%$ of the tumor area contained papillary structures composed of epithelial projections with a central fibrovascular core as a scaffold [17]. Histologic types of papillary adenocarcinoma were subclassified as pure papillary adenocarcinoma, papillary adenocarcinoma mixed with other differentiated-type carcinoma, and papillary adenocarcinoma mixed with undifferentiatedtype carcinoma (Fig. 2). The depth of tumor invasion was classified as mucosal or submucosal. Mucosal cancers were subdivided into $\mathrm{m} 1$ (confined to the epithelial layer), $\mathrm{m} 2$ (invasion into the lamina propria), and $\mathrm{m} 3$ (invasion into the muscularis mucosae) types, and submucosal cancers were subdivided into sm1 (submucosal invasion of $500 \mu \mathrm{m}$ or less from the muscularis mucosae) and sm2 (submucosal invasion of more than $500 \mu \mathrm{m}$ from the muscularis mucosae) types [17].

\section{Statistical analysis}

Continuous variables are expressed as median and ranges, and categorical variables are expressed as numbers and simple proportions. The Student $t$ test and one-way analysis of variance were used for comparisons of continuous variables, and the chi-square test or Fisher's exact test was performed for categorical variables. Predictive factors associated with LNM were analyzed by logistic regression analysis. Significant factors on univariate analysis, defined as $P<0.2$, or factors with clinical correlation were included in the multivariate model to assess the presence of independent factors associated with LNM. Multivariate comparisons are expressed as odds ratios with $95 \%$ confidence intervals. $P<0.05$ was considered statistically significant. Statistical analyses were performed with IBM SPSS Statistics version 21.0 (IBM, Armonk, NY, USA).
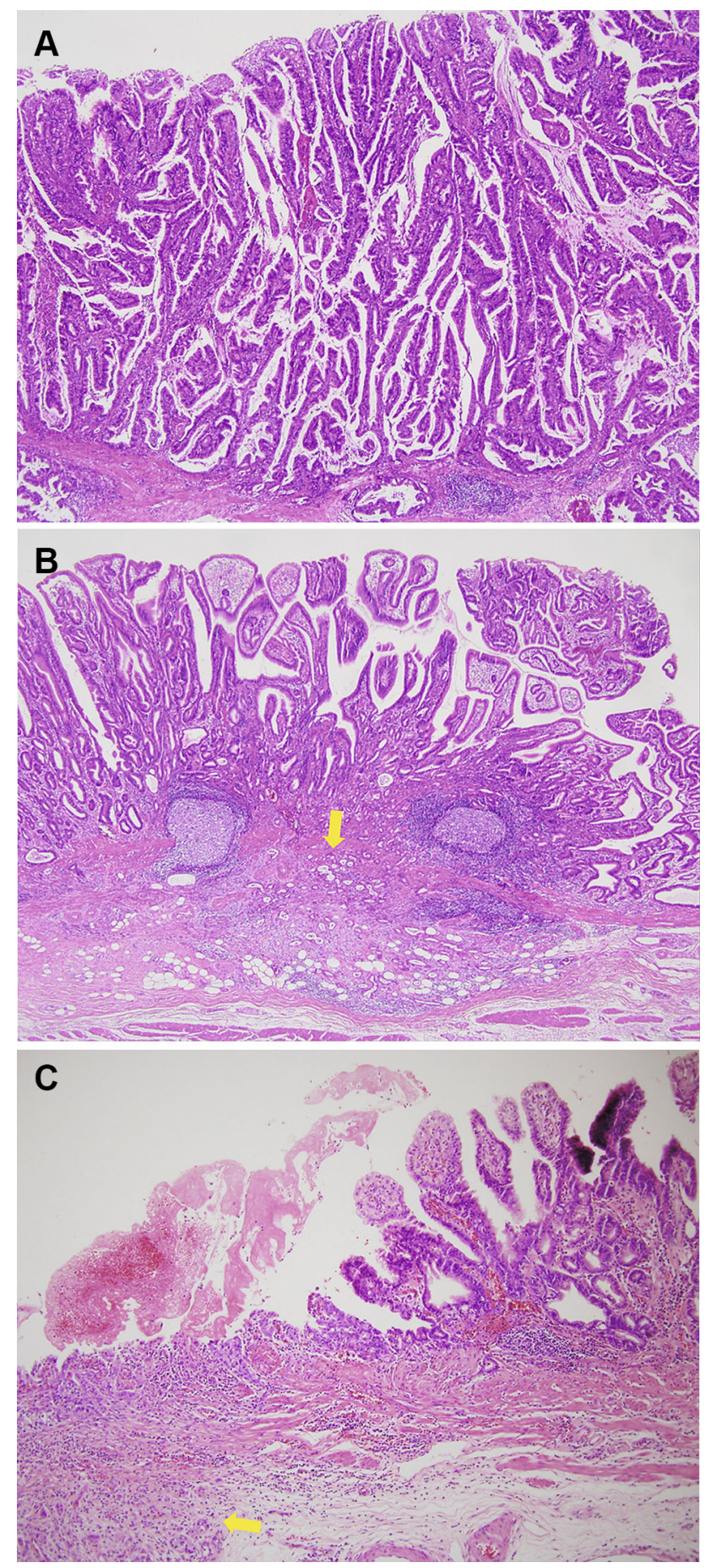

Fig. 2 Histologic types of papillary adenocarcinoma. a A case of pure papillary adenocarcinoma. The tumor is composed of fingerlike projections lined by atypical cuboidal cells with fibrovascular cores (hematoxylin and eosin staining, $\times 40$ ). b A case of papillary adenocarcinoma mixed with other differentiated-type adenocarcinoma. Papillary adenocarcinoma is seen in the superficial part of the tumor and well-differentiated tubular adenocarcinoma is seen in the invasive part of the tumor (arrow) (hematoxylin and eosin staining, $\times 40$ ). c A case of papillary adenocarcinoma mixed with undifferentiated-type carcinoma. Papillary adenocarcinoma is seen in the superficial part of the tumor and poorly cohesive carcinoma is seen in the invasive part of the tumor (arrow) (hematoxylin and eosin staining, $\times 100$ ) 


\section{Results}

\section{Clinicopathologic characteristics of patients with EGC-P and patients with EGC-NP}

Table 1 summarizes the clinicopathologic characteristics of the 56 patients with EGC-P and the 1527 patients with EGC-NP. Of the 1527 patients with EGC-NP, 859 had EGC-NP-D and 668 had EGC-NP-U. The median age of patients with EGC-P was 67 years (range 48-80 years), with a male predominance. The commonest location of EGC-P was the lower third of the stomach (43/56, 76.8\%), and the predilection of EGC-P for the lower third of the stomach was significantly higher than that of EGC-NP-D and EGC-NP-U $(76.8 \%$ vs $58.7 \%$ and $37.0 \% ; P=0.020$ and $P<0.001$ respectively). The predominant macroscopic shape of EGC-P was the elevated type (43/56, $76.8 \%$ ), whereas the predominant shape of EGC-NP-D and EGC-NP-U was the depressed type $(543 / 859,63.2 \%$, and $514 / 668,76.9 \%$, respectively). The median tumor size of EGC-P was $30 \mathrm{~mm}$ (range 9-76 mm), which was similar to that of EGC-NP-D and EGC-NP-U (25 and $26 \mathrm{~mm}$, respectively).

The frequency of submucosal invasion was significantly higher in EGC-P than in EGC-NP-D and EGC-NP-U (71.4\% vs $50.8 \%$ and $37.6 \% ; P=0.003$ and $P<0.001$ respectively). The frequency of LVI in EGC-P was $26.8 \%$ (14/56), which was significantly higher than that in EGCNP-D and EGC-NP-U (12.1\% and 6.9\% respectively; $P=0.002$ and $P<0.001$ respectively). The frequency of

Table 1 Clinicopathologic characteristics of patients with early gastric cancer with papillary adenocarcinoma $(E G C-P)$ and patients with early gastric cancer with nonpapillary adenocarcinoma $(E G C-N P)$

\begin{tabular}{|c|c|c|c|c|c|}
\hline & \multirow[t]{2}{*}{ EGC-P $(n=56)$} & \multicolumn{4}{|l|}{ EGC-NP $(n=1527)$} \\
\hline & & EGC-NP-D $(n=859)$ & $P$ & EGC-NP-U $(n=668)$ & $P$ \\
\hline Median age (years) ${ }^{a}$ & $67(49-80)$ & $63(27-90)$ & 0.001 & $55(24-85)$ & $<0.001$ \\
\hline Sex & & & 0.188 & & 0.007 \\
\hline Male & $39(69.6 \%)$ & $664(77.3 \%)$ & & $340(50.9 \%)$ & \\
\hline Female & $17(30.4 \%)$ & $195(22.7 \%)$ & & $328(49.1 \%)$ & \\
\hline Location & & & 0.020 & & $<0.001$ \\
\hline Upper third & $5(8.9 \%)$ & $92(10.7 \%)$ & & $63(9.4 \%)$ & \\
\hline Middle third & $8(14.3 \%)$ & $263(30.6 \%)$ & & $358(53.6 \%)$ & \\
\hline Lower third & $43(76.8 \%)$ & $504(58.7 \%)$ & & $247(37.0 \%)$ & \\
\hline Macroscopic shape ${ }^{b}$ & & & $<0.001$ & & $<0.001$ \\
\hline Elevated (I, IIa) & $43(76.8 \%)$ & $203(23.6 \%)$ & & $54(8.1 \%)$ & \\
\hline Flat (IIb) & $0(0 \%)$ & $113(13.2 \%)$ & & $100(15.0 \%)$ & \\
\hline Depressed (IIc, III) & $13(23.2 \%)$ & $543(63.2 \%)$ & & $514(76.9 \%)$ & \\
\hline Median tumor size $(\mathrm{mm})^{\mathrm{a}}$ & $30(9-105)$ & $25(2-140)$ & 0.174 & $26(2-130)$ & 0.480 \\
\hline Depth of invasion & & & 0.003 & & $<0.001$ \\
\hline Mucosa & $16(28.6 \%)$ & $423(49.2 \%)$ & & $417(62.4 \%)$ & \\
\hline $\mathrm{m} 1$ & 0 & 64 & & 69 & \\
\hline $\mathrm{m} 2$ & 1 & 45 & & 95 & \\
\hline $\mathrm{m} 3$ & 15 & 314 & & 253 & \\
\hline Submucosa & $40(71.4 \%)$ & $436(50.8 \%)$ & & $251(37.6 \%)$ & \\
\hline $\mathrm{sm} 1$ & 6 & 68 & & 29 & \\
\hline $\operatorname{sm} 2$ & 34 & 368 & & 222 & \\
\hline Lymphovascular invasion & $16(28.6 \%)$ & $104(12.1 \%)$ & 0.002 & $46(6.9 \%)$ & $<0.001$ \\
\hline Perineural invasion & $4(7.1 \%)$ & $40(4.6 \%)$ & 0.338 & $55(8.2 \%)$ & 0.812 \\
\hline Lymph node metastasis & $10(17.9 \%)$ & $84(9.8 \%)$ & 0.054 & $74(11.1 \%)$ & 0.130 \\
\hline
\end{tabular}

$E G C$-NP-D EGC-NP with differentiated-type histologic appearance, EGC-NP-U EGC-NP with undifferentiated-type histologic appearance, $m 1$ confined to the epithelial layer, $m 2$ invasion into the lamina propria, $m 3$ invasion into the muscularis mucosae, $s m 1$ submucosal invasion of $500 \mu \mathrm{m}$ or less from the muscularis mucosae, sm2 submucosal invasion of more than $500 \mu \mathrm{m}$ from the muscularis mucosae

${ }^{\text {a }}$ The range is given in parentheses

b Type I protruding, type IIa nonprotruding, nonexcavated, and slightly elevated, type IIb nonprotruding, nonexcavated, and flat, type IIc nonprotruding, nonexcavated, and slightly depressed, type III excavated 
LNM in EGC-P was $17.9 \%$ (10/56), which was higher than that in EGC-NP-D and EGC-NP-U (9.8\% and $11.1 \%$ respectively) but did not reach statistical significance ( $P=0.054$ and $P=0.130$ respectively). When the frequencies of submucosal invasion, LVI, and LNM in EGC-P were compared with those in each subtype of EGC-NP-D (well-differentiated and moderately differentiated adenocarcinoma) and EGC-NP-U (poorly differentiated adenocarcinoma and signet ring cell carcinoma), similar results were observed (Table S1).

\section{Predictive factors associated with LNM in EGC-P}

Predictive factors associated with LNM in EGC-P are summarized in Table 2. In univariate analyses, depth of invasion and histologic findings were not associated with LNM. The frequency of LNM was higher in tumors larger than $20 \mathrm{~mm}$ than in tumors of $20 \mathrm{~mm}$ or smaller, but this did not reach statistical significance $(23.0 \%$ vs $0 \%$, $P=0.052)$. Only LVI was associated with LNM in EGC-P $(P=0.003)$. On the basis of multivariate analysis, LVI was the sole predictive factor for LNM, with an odds ratio of $14.080(95 \%$ confidence interval 1.380-145.667, $P=0.026$; Table 2).

\section{Application of current ESD indication criteria to EGC-P}

Table 3 summarizes the frequencies of LNM and LVI in the 56 patients with EGC-P according to the current ESD indication criteria. Seven patients met the absolute ESD indication criteria (mucosal cancer $20 \mathrm{~mm}$ or smaller without ulceration) and ten met the expanded ESD indication criteria (five patients has mucosal cancer larger than $20 \mathrm{~mm}$ without ulceration, two patients had mucosal cancer $30 \mathrm{~mm}$ or smaller with ulceration, and three patients had sm1 cancer $30 \mathrm{~mm}$ or smaller). The other 39 patients did not meet the ESD indication criteria.

Of the 17 patients meeting the current ESD indication criteria, two patients $(11.8 \%)$ had LNM, including none of seven patients $(0 \%)$ meeting the absolute ESD indication criteria and two of ten patients $(20.0 \%)$ meeting the expanded ESD indication criteria (Table 4). Three patients $(3 / 17,17.6 \%)$ had LVI, including one of seven patients (16.7\%) meeting the absolute ESD indication criteria and two of ten patients $(20.0 \%)$ meeting the expanded ESD indication criteria. When LNM and LVI were combined, one of seven patients (16.7\%) meeting the absolute ESD indication criteria and three of ten patients $(30.0 \%)$ meeting the expanded ESD indication criteria would not be cured after ESD. Specifically, two of three patients $(66.7 \%)$ with sm1 cancer $30 \mathrm{~mm}$ or smaller had LVI or LNM.

\section{Discussion}

EGC-P showed higher frequencies of submucosal invasion, LVI, and LNM compared with EGC-NP. Furthermore, the overall incidence of LNM in the 56 patients with EGC-P was $17.9 \%$. Of the 17 patients who met the current ESD indication criteria, four patients $(23.5 \%)$ had LVI or LNM; this means that if the patients with EGC-P meeting the ESD indication criteria were to undergo ESD, about one fourth of these patients would require additional gastrectomy because of noncurative resection by ESD.

Papillary adenocarcinoma accounts for approximately $6-11 \%$ of gastric carcinomas and $1 \%$ of EGCs $[13,18,19]$. Because of the rarity of EGC-P, reports on its clinicopathologic characteristics are currently limited [13, 17]. In the present study, the frequency of papillary adenocarcinoma in EGCs was 3.5\% (56/1583). Patients with EGC-P were older, showed a trend toward distal tumor location and elevated shape, and had a higher rate of submucosal invasion, LVI, and LNM compared with those with EGC-NP.

The probability of LNM is a very important factor influencing the success of ESD for EGC, and tumor size, histologic type, depth of invasion, and LVI are recognized predictive factors of LNM [20]. The overall incidence of LNM in EGC is reported to be $10 \%$ (2-5\% for mucosal cancer vs more than $20 \%$ for submucosal cancer; $0.4 \%$ for differentiated-type intramucosal cancer vs $4.2-7.3 \%$ for undifferentiated-type intramucosal cancer) $[2,17,20,21]$. In the present study, tumor size, depth of invasion, and histologic type of papillary adenocarcinoma were not associated with LNM, and LVI was the sole predictive factor for LNM in EGC-P. The incidence of LNM in EGC$\mathrm{P}$ was $17.9 \%$ (6.3\% in mucosal cancer and $22.5 \%$ in submucosal cancer), which was higher than that in EGC-NP-D and EGC-NP-U. We also evaluated the safety of ESD for EGC-P by combining LNM and LVI. Of the 17 patients meeting the current ESD indication criteria, four patients $(23.5 \%)$ would not be cured after ESD alone, including one of seven patients meeting the absolute ESD indication criteria and three of ten patients meeting the expanded ESD indication criteria. Therefore, the current ESD indication criteria, especially the expanded ESD indication criteria, should not be applied to patients with EGC-P in the same manner it is applied to patients with EGC-NP-D.

The goal of ESD in the treatment of EGC is curative resection. However, because it is impossible to predict the final histopathologic results before ESD, the frequency of additional gastrectomy due to noncurative resection by ESD is reported to be 2.1-14.6\% [22, 23]. Additional gastrectomy is needed in cases with noncurative resection caused by positive horizontal or vertical margins, deep submucosal invasion (more than $500 \mu \mathrm{m}$ ), or the presence 
Table 2 Predictive factors associated with lymph node metastasis in early gastric cancers with papillary adenocarcinoma

\begin{tabular}{|c|c|c|c|c|}
\hline \multirow[t]{2}{*}{ Factor and number } & \multicolumn{2}{|c|}{ Univariate analysis } & \multicolumn{2}{|l|}{ Multivariate analysis } \\
\hline & Number & $P$ & Odds ratio $^{a}$ & $P$ \\
\hline Age & & 0.393 & & \\
\hline$\leq 60$ years $(11)$ & $3(27.3 \%)$ & & & \\
\hline$>60$ years $(45)$ & $7(15.6 \%)$ & & & \\
\hline Sex & & 0.471 & & \\
\hline Male (17) & $4(13.5 \%)$ & & & \\
\hline Female (39) & $6(15.4 \%)$ & & & \\
\hline Macroscopic findings & & 0.682 & & \\
\hline Elevated (43) & $7(16.3 \%)$ & & & \\
\hline Depressed (13) & $3(23.1 \%)$ & & & \\
\hline Tumor location & & 0.264 & & \\
\hline Upper third (5) & $0(0.0 \%)$ & & & \\
\hline Middle third (8) & $3(37.5 \%)$ & & & \\
\hline Lower third (43) & $7(16.3 \%)$ & & & \\
\hline Ulceration & & 0.698 & & \\
\hline Absent (42) & $7(16.7 \%)$ & & & \\
\hline Present (14) & $3(21.4 \%)$ & & & \\
\hline Tumor size & & 0.052 & & \\
\hline$\leq 20 \mathrm{~mm}(14)$ & $0(0.0)$ & & & \\
\hline$>20 \mathrm{~mm}(42)$ & $10(23.8 \%)$ & & & \\
\hline Invasion depth & & 0.251 & & \\
\hline Mucosa (16) & $1(6.3 \%)$ & & & \\
\hline Submucosa (40) & $9(22.5 \%)$ & & & \\
\hline Histologic findings & & 0.684 & & \\
\hline PP (34) & $5(14.7 \%)$ & & & \\
\hline MP-D (14) & $3(21.4 \%)$ & & & \\
\hline MP-U (8) & $2(25.0 \%)$ & & & \\
\hline Lymphovascular invasion & & 0.003 & & \\
\hline Absent (40) & $3(7.5 \%)$ & & 1 (reference) & \\
\hline Present (10) & $7(43.8 \%)$ & & $14.180(1.380-145.667)$ & 0.026 \\
\hline
\end{tabular}

of LVI [24, 25]. When current ESD indication criteria were applied to EGC-P patients included in the present study, one of seven patients $(16.7 \%)$ meeting the absolute ESD indication criteria and two of ten patients $(20.0 \%)$ meeting the expanded ESD indication criteria had LVI. As a result, 3 of 17 patients $(17.6 \%)$ should undergo additional gastrectomy because of noncurative resection as a result of LVI. This rate is higher than the rates in the aforementioned studies [22, 23].

In the present study, we included only patients who ultimately had a diagnosis of EGC-P after gastrectomy. Even though papillary adenocarcinoma exists within a tumor, it might not be diagnosed on pre-ESD biopsy because of the very small amount of specimen obtained by endoscopic biopsy and tangential sectioning of specimens.
Pre-ESD biopsy sometimes shows a different histologic appearance than that seen in the post-ESD specimen, which can be attributed to interobserver and intraobserver variability as well as the fact that gastric cancer can show histologic heterogeneity [26, 27]. We attempted to analyze whether it was possible to diagnose papillary adenocarcinoma by endoscopic biopsy alone, but it was very difficult because of inaccessibility to previous endoscopic biopsy slides, tangential sectioning of specimens, and mixed-histologic-type tumors. The percentage of accessible cases that we could diagnose retrospectively with papillary adenocarcinoma was less than $20 \%$ (data not shown). Therefore, it is helpful to correctly predict the possibility of papillary carcinoma before ESD. Recently, the presence of a "vessels within epithelial circle" pattern as visualized by 
Table 3 Clinicopathologic characteristics of patients with early gastric cancer with papillary adenocarcinoma who met the current indication criteria for endoscopic submucosal dissection

\begin{tabular}{|c|c|c|c|c|c|c|c|c|c|c|}
\hline $\begin{array}{l}\text { Patient } \\
\text { no. }\end{array}$ & $\begin{array}{l}\text { Sex/age } \\
\text { (years) }\end{array}$ & $\begin{array}{l}\text { Tumor } \\
\text { location }\end{array}$ & $\begin{array}{l}\text { Macroscopic } \\
\text { type }^{\mathrm{a}}\end{array}$ & Ulceration & $\begin{array}{l}\text { Histologic } \\
\text { type }\end{array}$ & $\begin{array}{l}\text { Tumor size } \\
(\mathrm{mm})\end{array}$ & $\begin{array}{l}\text { Invasion } \\
\text { depth }\end{array}$ & LVI & LNM & $\begin{array}{l}\text { ESD } \\
\text { indication }\end{array}$ \\
\hline 1 & $\mathrm{M} / 59$ & Lower third & IIa & - & PP & 9 & $\mathrm{~m} 3$ & - & - & Absolute \\
\hline 2 & $\mathrm{M} / 60$ & Lower third & IIa & - & PP & 12 & $\mathrm{~m} 3$ & - & - & Absolute \\
\hline 3 & $\mathrm{~F} / 76$ & Lower third & IIa & - & $\mathrm{PP}$ & 13 & $\mathrm{~m} 3$ & - & - & Absolute \\
\hline 4 & M/66 & Lower third & IIa & - & PP & 14 & $\mathrm{~m} 3$ & - & - & Absolute \\
\hline 5 & $\mathrm{~F} / 73$ & Lower third & I & - & $\mathrm{PP}$ & 15 & $\mathrm{~m} 3$ & - & - & Absolute \\
\hline 6 & $\mathrm{~F} / 76$ & Lower third & IIa & - & PP & 18 & $\mathrm{~m} 2$ & - & - & Absolute \\
\hline 7 & $\mathrm{M} / 74$ & Upper third & IIa & - & PP & 18 & $\mathrm{~m} 3$ & + & - & Absolute \\
\hline 8 & $\mathrm{M} / 62$ & Lower third & IIa & - & $\mathrm{PP}$ & 29 & $\mathrm{~m} 3$ & - & - & Expanded \\
\hline 9 & $\mathrm{M} / 63$ & Lower third & IIa & - & PP & 43 & $\mathrm{~m} 3$ & - & - & Expanded \\
\hline 10 & $\mathrm{M} / 58$ & Mid third & IIa & - & MP-D & 48 & $\mathrm{~m} 3$ & - & + & Expanded \\
\hline 11 & $\mathrm{~F} / 72$ & Lower third & I & - & $\mathrm{PP}$ & 50 & $\mathrm{~m} 3$ & - & - & Expanded \\
\hline 12 & $\mathrm{~F} / 65$ & Lower third & $\mathrm{I}+\mathrm{IIa}$ & - & PP & 60 & $\mathrm{~m} 3$ & - & - & Expanded \\
\hline 13 & M/64 & Lower third & IIc & + & $\mathrm{PP}$ & 20 & $\mathrm{~m} 3$ & - & - & Expanded \\
\hline 14 & $\mathrm{M} / 62$ & Lower third & IIc & + & $\mathrm{PP}$ & 30 & $\mathrm{~m} 3$ & - & - & Expanded \\
\hline 15 & M/66 & Lower third & IIc & + & $\mathrm{PP}$ & 25 & $\mathrm{sm} 1$ & - & - & Expanded \\
\hline 16 & $F / 76$ & Lower third & IIa & - & MP-D & 25 & sm1 & + & - & Expanded \\
\hline 17 & $\mathrm{~F} / 63$ & Lower third & IIa & - & MP-D & 30 & $\mathrm{sm} 1$ & + & + & Expanded \\
\hline
\end{tabular}

ESD endoscopic submucosal dissection, $F$ female, $L N M$ lymph node metastasis, $L V I$ lymphovascular invasion, $M$ male, $m 2$ invasion into the lamina propria, $m 3$ invasion into the muscularis mucosae, $M P-D$ papillary adenocarcinoma mixed with other differentiated-type carcinoma, $P P$ pure papillary adenocarcinoma, $s m 1$ submucosal invasion of $500 \mu \mathrm{m}$ or less from the muscularis mucosae,

a Type I protruding, type IIa nonprotruding, nonexcavated, and slightly elevated, type IIc nonprotruding, nonexcavated, and slightly depressed

Table 4 Lymph node metastasis and lymphovascular invasion in early gastric cancers with papillary adenocarcinoma according to the current indication criteria for endoscopic submucosal dissection

\begin{tabular}{|c|c|c|c|c|c|c|c|}
\hline & \multicolumn{4}{|c|}{ Mucosal cancer $(n=16)$} & \multicolumn{3}{|c|}{ Submucosal cancer $(n=40)$} \\
\hline & \multicolumn{2}{|c|}{ Ulcer negative $(n=12)$} & \multicolumn{2}{|c|}{ Ulcer positive $(n=4)$} & \multicolumn{2}{|c|}{$\operatorname{sm} 1(n=6)$} & \multirow{2}{*}{$\begin{array}{l}\operatorname{sm} 2(n=34) \\
\text { Any size } \\
(n=34)\end{array}$} \\
\hline & $\begin{array}{l}\leq 20 \mathrm{~mm} \\
(n=7)\end{array}$ & $\begin{array}{l}>20 \mathrm{~mm} \\
(n=5)\end{array}$ & $\begin{array}{l}\leq 30 \mathrm{~mm} \\
(n=2)\end{array}$ & $\begin{array}{l}>30 \mathrm{~mm} \\
(n=2)\end{array}$ & $\begin{array}{l}\leq 30 \mathrm{~mm} \\
(n=3)\end{array}$ & $\begin{array}{l}>30 \mathrm{~mm} \\
(n=3)\end{array}$ & \\
\hline LNM & $0(0 \%)$ & $1(20 \%)$ & $0(0 \%)$ & $0(0 \%)$ & $1(33.3 \%)$ & $0(0 \%)$ & $8(23.5 \%)$ \\
\hline LVI & $1(16.7 \%)$ & $0(0 \%)$ & $0(0 \%)$ & $0(0 \%)$ & $2(66.7 \%)$ & $1(33.3 \%)$ & $12(35.3 \%)$ \\
\hline $\begin{array}{l}\text { LNM or } \\
\text { LVI }\end{array}$ & $1(16.7 \%)$ & $1(20 \%)$ & $0(0 \%)$ & $0(0 \%)$ & $2^{\mathrm{a}}(66.7 \%)$ & $1(33.3 \%)$ & $13(38.2 \%)$ \\
\hline
\end{tabular}

LNM lymph node metastasis, LVI lymphovascular invasion, sm1 submucosal invasion of $500 \mu \mathrm{m}$ or less from the muscularis mucosae, $s m 2$ submucosal invasion of more than $500 \mu \mathrm{m}$ from the muscularis mucosae

${ }^{a}$ One patient had both LVI and LNM

magnifying endoscopy with narrow band imaging was reported to be helpful in the diagnosis of papillary adenocarcinoma [28].

The explanation for the increased malignant potential of papillary adenocarcinoma compared with other histologic types is unclear. Recently, cannibalism-mediated chromosomal instability and aneuploidy (although this phenomenon was found in the deep micropapillary component of papillary carcinoma) [29] and a high incidence of Brm deficiency having an antineoplastic role [30] have been suggested to be factors associated with the aggressive behavior of papillary adenocarcinoma. Further studies to elucidate the pathogenesis of the high malignant potential of papillary carcinoma are warranted.

Our study has some limitations. First, since we retrospectively included patients with EGC-P who underwent 
gastrectomy, potential selection biases might have been present. Second, we enrolled a relatively small number of patients with EGC-P in a single center and did not include long-term follow-up data, such as recurrence or survival, in these patients. Large-scale multicenter studies with a longterm follow-up period are needed to clarify our results. Third, because a tumor's histopathologic type is typically defined as the predominant type in cases with mixed histopathologic components, we defined papillary adenocarcinoma as a tumor in which more than $50 \%$ of the tumor area contained papillary structures [17]. Several studies have shown that the clinicopathologic characteristics and outcomes of EGC with mixed histologic type are different from those of EGC with one pure histologic type $[4,5,24,31]$. Therefore, other histopathologic components in EGC-P might confer different clinicopathologic characteristics.

In conclusion, our study demonstrated that the frequency of submucosal invasion was significantly higher in EGC-P than in EGC-NP-D and EGC-NP-U and that the frequencies of LNM and LVI, according to the current ESD indication criteria, were high $(11.8 \%$ and $17.6 \%$ respectively). Therefore, the use of ESD should be more carefully applied in the treatment of EGC-P meeting the ESD indication criteria, especially the expanded indication criteria, after pretreatment workup compared with other differentiated-type adenocarcinomas, because of the higher frequencies of submucosal invasion, LNM, and LVI in EGCP.

Acknowledgements This study was supported by a grant from the National R\&D Program for Cancer Control, Ministry for Health, Welfare and Family Affairs, Republic of Korea (0920050), and by the Medical Research Center Program through a National Research Foundation of Korea grant funded by the Korean government (NRF2015R1A5A2009656).

\section{Compliance with ethical standards}

Conflict of interest The authors declare that they have no conflict of interest.

Human rights statement and informed consent All procedures followed were in accordance with the ethical standards of the responsible committee on human experimentation (institutional and national) and with the Declaration of Helsinki of 1964 and later versions. Informed consent or a substitute for it was obtained from all patients for their being included in the study.

\section{References}

1. Jeong O, Park YK. Clinicopathological features and surgical treatment of gastric cancer in South Korea: the results of 2009 nationwide survey on surgically treated gastric cancer patients. J Gastric Cancer. 2011;11:69-77.
2. Gotoda T, Yanagisawa A, Sasako M, Ono H, Nakanishi Y, Shimoda $\mathrm{T}$, et al. Incidence of lymph node metastasis from early gastric cancer: estimation with a large number of cases at two large centers. Gastric Cancer. 2000;3:219-25.

3. Park WY, Shin N, Kim JY, Jeon TY, Kim GH, Kim H, et al. Pathologic definition and number of lymphovascular emboli: impact on lymph node metastasis in endoscopically resected early gastric cancer. Hum Pathol. 2013;44:2132-8.

4. Min BH, Kim KM, Park CK, Lee JH, Rhee PL, Rhee JC, et al. Outcomes of endoscopic submucosal dissection for differentiated-type early gastric cancer with histological heterogeneity. Gastric Cancer. 2015;18:618-26.

5. Han JP, Hong SJ, Kim HK. Long-term outcomes of early gastric cancer diagnosed as mixed adenocarcinoma after endoscopic submucosal dissection. J Gastroenterol Hepatol. 2015;30:316-20.

6. Shin DW, Hwang HY, Jeon SW. Comparison of endoscopic submucosal dissection and surgery for differentiated type early gastric cancer within the expanded criteria. Clin Endosc. 2016. doi:10.5946/ce.2016.017.

7. Fukunaga S, Nagami Y, Shiba M, Ominami M, Tanigawa T, Yamagami H, et al. Long-term prognosis of expanded-indication differentiated-type early gastric cancer treated with endoscopic submucosal dissection or surgery using propensity score analysis. Gastrointest Endosc. 2017;85:143-52.

8. Abe S, Oda I, Suzuki H, Nonaka S, Yoshinaga S, Odagaki T, et al. Short- and long-term outcomes of endoscopic submucosal dissection for undifferentiated early gastric cancer. Endoscopy. 2013;45:703-7.

9. Choi MK, Kim GH, Park DY, Song GA, Kim DU, Ryu DY, et al. Long-term outcomes of endoscopic submucosal dissection for early gastric cancer: a single-center experience. Surg Endosc. $2013 ; 27: 4250-8$.

10. Japanese Gastric Cancer Association. Japanese classification of gastric carcinoma: 3rd English edition. Gastric Cancer. 2011;14:101-12.

11. Lauren P. The two, histological main types of gastric carcinoma: diffuse and so-called intestinal-type carcinoma. An attempt at a histo-clinical classification. Acta Pathol Microbiol Scand. 1965;64:31-49.

12. Kim HM, Pak KH, Chung MJ, Cho JH, Hyung WJ, Noh SH, et al. Early gastric cancer of signet ring cell carcinoma is more amenable to endoscopic treatment than is early gastric cancer of poorly differentiated tubular adenocarcinoma in select tumor conditions. Surg Endosc. 2011;25:3087-93.

13. Yasuda K, Adachi Y, Shiraishi N, Maeo S, Kitano S. Papillary adenocarcinoma of the stomach. Gastric Cancer. 2000;3:33-8.

14. Sekiguchi M, Sekine S, Oda I, Nonaka S, Suzuki H, Yoshinaga S, et al. Risk factors for lymphatic and venous involvement in endoscopically resected gastric cancer. J Gastroenterol. 2013;48:706-12.

15. Sekiguchi M, Kushima R, Oda I, Suzuki H, Taniguchi H, Sekine $\mathrm{S}$, et al. Clinical significance of a papillary adenocarcinoma component in early gastric cancer: a single-center retrospective analysis of 628 surgically resected early gastric cancers. J Gastroenterol. 2015;50:424-34.

16. Yamada T, Sugiyama H, Ochi D, Akutsu D, Suzuki H, Narasaka $\mathrm{T}$, et al. Risk factors for submucosal and lymphovascular invasion in gastric cancer looking indicative for endoscopic submucosal dissection. Gastric Cancer. 2014;17:692-6.

17. Lee HJ, Kim GH, Park DY, Lee BE, Jeon HK, Jhi JH, et al. Is endoscopic submucosal dissection safe for papillary adenocarcinoma of the stomach? World J Gastroenterol. 2015;21:3944-52.

18. Uefuji K, Ichikura T, Tamakuma S. Clinical and prognostic characteristics of papillary clear carcinoma of stomach. Surg Today. 1996;26:158-63. 
19. Xuan ZX, Ueyama T, Yao T, Tsuneyoshi M. Time trends of early gastric carcinoma. A clinicopathologic analysis of 2846 cases. Cancer. 1993;72:2889-94.

20. Kim KJ, Park SJ, Moon W, Park MI. Analysis of factors related to lymph node metastasis in undifferentiated early gastric cancer. Turk J Gastroenterol. 2011;22:139-44.

21. Akagi T, Shiraishi N, Kitano S. Lymph node metastasis of gastric cancer. Cancers (Basel). 2011;3:2141-59.

22. Jung H, Bae JM, Choi MG, Noh JH, Sohn TS, Kim S. Surgical outcome after incomplete endoscopic submucosal dissection of gastric cancer. Br J Surg. 2011;98:73-8.

23. Noh H, Park JJ, Yun JW, Kwon M, Yoon DW, Chang WJ, et al. Clinicopathologic characteristics of patients who underwent curative additional gastrectomy after endoscopic submucosal dissection for early gastric cancer or adenoma. Korean J Gastroenterol. 2012;59:289-95.

24. Takizawa K, Ono H, Kakushima N, Tanaka M, Hasuike N, Matsubayashi $\mathrm{H}$, et al. Risk of lymph node metastases from intramucosal gastric cancer in relation to histological types: how to manage the mixed histological type for endoscopic submucosal dissection. Gastric Cancer. 2013;16:531-6.

25. Fujii M, Egashira Y, Akutagawa H, Nishida T, Nitta T, Edagawa $\mathrm{G}$, et al. Pathological factors related to lymph node metastasis of submucosally invasive gastric cancer: criteria for additional gastrectomy after endoscopic resection. Gastric Cancer. 2013;16:521-30.
26. Luinetti O, Fiocca R, Villani L, Alberizzi P, Ranzani GN, Solcia E. Genetic pattern, histological structure, and cellular phenotype in early and advanced gastric cancers: evidence for structurerelated genetic subsets and for loss of glandular structure during progression of some tumors. Hum Pathol. 1998;29:702-9.

27. Kim JM, Sohn JH, Cho MY, Kim WH, Chang HK, Jung ES, et al. Pre- and post-ESD discrepancies in clinicopathologic criteria in early gastric cancer: the NECA-Korea ESD for early gastric cancer prospective study (N-Keep). Gastric Cancer. 2016;19:1104-13.

28. Kanemitsu T, Yao K, Nagahama T, Fujiwara S, Takaki Y, Ono Y, et al. The vessels within epithelial circle (VEC) pattern as visualized by magnifying endoscopy with narrow-band imaging (ME$\mathrm{NBI}$ ) is a useful marker for the diagnosis of papillary adenocarcinoma: a case-controlled study. Gastric Cancer. 2014;17:469-77.

29. Barresi V, Branca G, Ieni A, Rigoli L, Tuccari G, Caruso RA. Phagocytosis (cannibalism) of apoptotic neutrophils by tumor cells in gastric micropapillary carcinomas. World J Gastroenterol. 2015;21:5548-54.

30. Yamamichi N, Inada $K$, Ichinose $M$, Yamamichi-Nishina $M$, Mizutani T, Watanabe H, et al. Frequent loss of Brm expression in gastric cancer correlates with histologic features and differentiation state. Cancer Res. 2007;67:10727-35.

31. Hanaoka N, Tanabe S, Mikami T, Okayasu I, Saigenji K. Mixedhistologic-type submucosal invasive gastric cancer as a risk factor for lymph node metastasis: feasibility of endoscopic submucosal dissection. Endoscopy. 2009;41:427-32. 